Phillip Dawson, MONASH UNIVERSITY, phillip.dawson@monash.edu.au

Margaret Bearman, MONASH UNIVERSITY, margaret.bearman@monash.edu.au David J. Boud, UNIVERSITY OF TECHNOLOGY, SYDNEY, david.boud@uts.edu.au

Matt Hall, MONASH UNIVERSITY, matt.hall@monash.edu.au Elizabeth K. Molloy, MONASH UNIVERSITY, elizabeth.molloy@monash.edu.au Sue Bennett, UNIVERSITY OF WOOLONGONG, susan.bennett@uow.edu.au Gordon Joughin, UNIVERSITY OF QUEENSLAND, g.joughin@uq.edu.au

\title{
Assessment Might Dictate the Curriculum, but What Dictates Assessment?
}

\begin{abstract}
Almost all tertiary educators make assessment choices, for example, when they create an assessment task, design a rubric, or write multiple-choice items. Educators potentially have access to a variety of evidence and materials regarding good assessment practice but may not choose to consult them or be successful in translating these into practice. In this article, we propose a new challenge for the Scholarship of Teaching and Learning: the need to study the disjunction between proposals for assessment "best practice" and assessment in practice by examining the assessment decision-making of teachers. We suggest that assessment decision-making involves almost all university teachers, occurs at multiple levels, and is influenced by expertise, trust, culture, and policy. Assessment may dictate the curriculum from the student's perspective, and we argue that assessment decision-making dictates assessment.
\end{abstract}

\section{KEYWORDS}

assessment, decision-making, design; research, evidence.

Assessment of learning is a core concern of the Scholarship of Teaching and Learning as it is necessary for students and represents a routine part of a university teacher's work; as Boud (1995) states, "Students can, with difficulty, escape from the effects of poor teaching, they cannot (by definition if they want to graduate) escape the effects of poor assessment" (p. 35). It is also a particularly demanding part of academic life. Price et al. (2011) note "achieving a balance between summative and formative assessment requires complex, contextual thinking," contending that part of the problem with current assessment thinking may be "oversimplified or poor decision-making" (p. 486). As assessment is so central to higher education and presents significant challenges for university teachers, it provides a key arena for exploring how academics' decisions can shape the educational environment.

Assessment can be thought of as making 'judgements about students' work, inferring from this what they have the capacity to do in the assessed domain, and thus what they know, value, or are capable of doing" (Joughin, 2009, p. 16). While the individual mark 
or feedback may appear the most important component of assessment to an individual student (or educator), we argue that this judgement should in many ways be considered the least important factor affecting the assessment process. The shaping of the assessment task, including such factors as purpose, timing, and co-curricular activities, may be more critical for the impact on learners and learning. We call the choices that frame the assessment "assessment decisions." It may be helpful to consider "assessment decisions" across three levels, which occur at quite different points of time and may involve different people. (See Table 1).

Table 1 Three Levels of Assessment Decisions with Questions commonly Asked at Each Level

DECISION LEVEL QUESTIONS ASKED

\begin{tabular}{|c|c|}
\hline $\begin{array}{l}\text { Curriculum level decisions } \\
\text { - often made well in advance with sub- } \\
\text { stantial committee oversight }\end{array}$ & $\begin{array}{l}\text { - How many assessments will this subject have, and what is } \\
\text { their nature? } \\
\text { - Will I put the paperwork in to replace that examination with a } \\
\text { project, even though it won't come into effect until next year? }\end{array}$ \\
\hline $\begin{array}{l}\text { Pedagogy level decisions } \\
\text { - usually performed prior to the start } \\
\text { of a semester when preparing syllabus } \\
\text { documents or subject outlines }\end{array}$ & $\begin{array}{l}\text {-Will I design a rubric for this task, and if so, will I consult stu- } \\
\text { dents in its design? } \\
\text {-What format will the final exam take? }\end{array}$ \\
\hline $\begin{array}{l}\text { Operational level decisions } \\
\text { - frequently required by day-to-day } \\
\text { teaching activities }\end{array}$ & $\begin{array}{l}\text { - How will I provide feedback to students about a topic they } \\
\text { seem to misunderstand? } \\
\text { - My grades appear to be much higher than the other markers, } \\
\text { should I do something about that? } \\
\text { - I'm running out of time to mark these assignments, can I } \\
\text { achieve the same learning outcomes if I give brief feedback? }\end{array}$ \\
\hline
\end{tabular}

The cumulative implications of these assessment decisions are not currently well understood. This may be partly because assessment decision-making is often dispersed across the academic workforce, with not all academics having responsibility for making decisions across all levels. If we include sessional and part-time tutors or teaching assistants, a substantial body of university teachers might only make decisions at an operational level, while decisions at the curriculum and pedagogy levels might be deferred to more experienced, tenured or full-time university teachers. Conversely, some senior academics might not be involved in decisions at the operational level because of the engagement of sessional staff. This simple example of the impact of employment status reveals the critical influence of the context upon educators' capacity to make changes. It is impossible to advocate a study of assessment decisions which does not take into consideration the influences of the academic practice environment.

The previous example highlights the issue of knowledge translation (Straus, Tetroe \& Graham, 2009), where understanding how 'good' assessment practice in a theoretical sense may not result in its application within a particular local context. This difference has been identified by Eley (2006), who empirically studied the gap between educational theory and enacted educational decision-making. His work described teachers' emphasis on the local immediate context rather than accessing "higher level conceptions of prac- 
tice. Similarly, recent case studies in assessment 'thinking' in higher education indicated that, although university teachers could learn more sophisticated thinking about assessment, this may not lead to changed assessment practices" (Offerdahl \& Tomanek, 2011).

We argue that it is likely there are many factors influencing this 'gap.' For example, it might be that expertise plays a role in assessment decisions. Kreber's (2002) categories of excellent, expert, and scholarly teachers may be helpful. Kreber suggests that excellent teachers make somewhat intuitive decisions, informed by their experiences, whereas expert teachers are able to articulate the (often scholarly) evidence or rationale that informs their choices. Scholarly teachers advance beyond expert teachers by sharing and systematising their decisions. Good assessment practices are likely to be influenced by more than just assessment expertise: if you lack the time to make criteria explicit to students, then you may choose not to; if your departmental culture opposes peer feedback then you might avoid it; if you are employed on a short-term contract you might not choose to make long-term curricular changes. Kreber argues that incentives for excellent practice are often not substantial enough for teachers to move beyond 'good enough' practice, and we propose this may also influence assessment decisions.

Another factor which may be particularly pertinent to assessment decision-making is the diversity of perspectives on the primary purpose of assessment. Assessment always performs multiple functions (Boud, 2000). In addition to its stated aims of assessing specified learning outcomes, it acts to both overtly and implicitly communicate what is valued by a profession or discipline. Moreover, while we often consider assessment's summative, certifying and credentialing role, assessment also serves formative and developmental ends. An individual university teacher's view of the purposes of assessment might influence the assessment decisions they make. When faced with the opportunity to choose between a final examination or frequent low-stakes assessment, a university teacher who believes the role of assessment is rigorous certification may make a different decision to a teacher who privileges assessment's developmental role. These beliefs may be unconscious or unstated, but possibly shape assessment decisions.

Institutional policies, which tend to emphasise rigorous credentialing (Boud, 2007), must also have a large influence upon assessment decisions, but it is not clear to what degree these policies affect assessment decisions made by university teachers. Emerging research with Australian university teachers suggests they have "reasonable scope to make important decisions about what and how they teach" (Bennett, et al. 2011, p. 164); this flexibility extends to assessment decisions. Are these decisions made in accord with policy or in spite of it? Price et al. (2011) identify a difficulty working within assessment frameworks which must meet institutional requirements; they are often set well in advance and are unresponsive to changes in practice. Additionally, any assessment regime must also be sustained over time and across different personnel. Further, some assessment strategies may be more demanding on teacher or student than is practicable. Decisions about assessment may also be driven by increases in student numbers and reductions in funding. The trend towards modularised programs may reduce opportunities for formative assessment because tasks must be slotted into shorter teaching blocks. These contextual tensions increase the difficulty of what are already complex assessment decision-making tasks.

The issue of 'trust' further complicates the 'assessment decisions' landscape. Carless (2009) argues that we sometimes shy away from more innovative forms of assessment in favour of traditional forms because proven methods are perceived as trustworthy and 
reliable. Privileging the perceived trustworthiness of multiple-choice testing might lead to the decision for a high-stakes exam at the cost of long-term learning. While this assessment type might mitigate plagiarism (Carless, 2009), it may lead to learning of false facts from engagement with the alternative but incorrect options (Marsh, et al. 2007) or simply promote study strategies that emphasis memorisation. Conversely, a sense of trust may positively influence assessment, particularly when it leads to shared decision-making involving on-the-ground academics and middle and senior management (Carless, 2009).

Ramsden (1992) popularized the notion that assessment defines the curriculum for students. We argue that assessment decision-making is the antecedent of this. Assessment practice is mediated by decisions that are currently poorly understood, but may be influenced by a variety of factors. Unaddressed research questions are plentiful and include the following: What contextual (or other) factors influence the assessment decisions made by university teachers? How do university teachers make decisions about assessment? Who makes what sorts of assessment decisions, and when do they make them? We urge scholars of learning and teaching to move beyond the study of abstracted assessment practices to understand how assessment principles can translate to improve outcomes in local contexts.

Phillip Dawson is a lecturer in Learning and Teaching, Office of the Pro Vice-Chancellor (Learning and Teaching), Monash University.

Margaret Bearman is a senior lecturer in the Health Professions Education and Educational Research Team, (HealthPEER) within the Faculty of Medicine, Nursing and Health Sciences, Monash University.

David Boud is Professor in the Faculty of Arts and Social Sciences, University of Technology Sydney.

Matt Hall is Educational Excellence Coordinator in the Office of the Pro Vice-Chancellor (Learning and Teaching), Monash University.

Elizabeth Molloy is director of the HealthPEER team in the Faculty of Medicine, Nursing and Health Sciences, Monash University.

Sue Bennett is Associate Professor of ICT in Education and Director of the Education IT Centre in the Faculty of Education, University of Wollongong.

Gordon Joughin is Acting Director of the Teaching and Educational Development Institute (TEDI), University of Queensland and a Visiting Professor at Leeds Metropolitan University.

\section{REFERENCES}

Bennett, S., Thomas, L., Agostinho, S., Lockyer, L., Jones, J., \& Harper, B. (2011). Understanding the design context for Australian university teachers: Implications for the future of learning design. Learning, Media and Technology, 36(2), 151-167. doi: 10.1080/17439884.2011.553622

Boud, D. (1995). Assessment and learning: Contradictory or complementary. In P. Knight (Ed.), Assessment for Learning in Higher Education (pp. 35-48). London: Kogan Page.

Boud, D. (2000). Sustainable Assessment: Rethinking assessment for the learning society. Studies in Continuing Education, 22(2), 151-167. doi: 10.1080/713695728

Boud, D. (2007). Reframing assessment as if learning were important. In D. Boud \& N. Falchikov (Eds.), Rethinking Assessment in Higher Education: Learning for the longer term (pp. 14-28). London: Routledge. 
Carless, D. (2009). Trust, distrust and their impact on assessment reform. Assessment \& Evaluation in Higher Education, 34(1), 79-89. doi: 10.1080/02602930801895786

Eley, M. (2006). Teachers' conceptions of teaching, and the making of specific decisions in planning to teach. Higher Education, 51(2), 191-214. doi: 10.1007/s10734-004-6382-9

Joughin, G. (2009). Assessment, learning and judgement in higher education: A critical review. In G. Joughin (Ed.), Assessment, Learning and Judgement in Higher Education (pp. 13-27): Springer Netherlands.

Kreber, C. (2002). Teaching excellence, teaching expertise, and the scholarship of teaching. Innovative Higher Education, 27(1), 5-23. doi: 10.1023/a:1020464222360

Marsh, E., Roediger, H., Bjork, R., \& Bjork, E. (2007). The memorial consequences of multiplechoice testing. Psychonomic Bulletin \& Review, 14(2), 194-199. doi: 10.3758/bf03194051

Offerdahl, E. G., \& Tomanek, D. (2011). Changes in instructors' assessment thinking related to experimentation with new strategies. Assessment \& Evaluation in Higher Education, 36(7), 781-795. doi: 10.1080/02602938.2010.488794

Price, M., Carroll, J., O’Donovan, B., \& Rust, C. (2011). If I was going there I wouldn't start from here: A critical commentary on current assessment practice. Assessment \& Evaluation in Higher Education, 36(4), 479-492. doi: 10.1080/02602930903512883

Ramsden, P. (1992). Learning to teach in higher education. London: Routledge.

Straus, S.E., Tetroe, J., \& Graham, I. (2009) Defining knowledge translation. Canadian Medical Association Journal, 181(3-4), 165-168. 